\title{
Trends in Total Precipitation and Frequency of Daily Precipitation Extremes
}

\author{
Yanwei Zhang ${ }^{1}$ and Wenwen Wang ${ }^{1, a)}$ \\ ${ }^{1}$ Soft Power Research Centre of Business College, University of Jinan, Jinan 250002, China. \\ a)Corresponding author: Wangwen16688@163.com
}

\begin{abstract}
Keywords: Total Precipitation; Frequency; Precipitation Extremes
Abstract. Base on daily precipitation dataset of 55 stations in Xinjiang, China and apply STARS (Sequential t-test analysis of regime shifts) techniques, trends in annual and seasonal total precipitation and extreme daily precipitation, assessed for 1961-2008. The results indicate that there is little trend in total precipitation for Xinjiang as a whole, but there are distinctive regional and seasonal patterns of trends. During of 1961-2000, there were two regimes of the annual total precipitation; one shift happened in 1987. Before the shift, are-averaged time series of annual total precipitation was $118.6 \mathrm{~mm}$ cubic meters per year; after that, it decreased and are-averaged time series of annual total precipitation was $145.8 \mathrm{~mm}$ per year.
\end{abstract}

\section{Introduction}

Temperature and precipitation play an important role in the global water and energy cycle. Since 1880a, the year 2008a ranked as the 9th warmest year on record, the warmest years were all among the recent 12 years from 1997 to 2008a, indicicatinous trend of global warming (Xu Yuqing et al. 2009). Now, floods, severe and persistent droughts, snow storms, heat waves and cold waves, were recorded in many parts of the word. In recent years, European region have experienced several extreme episodes, such as the devastating summer 2002 floods in Central Europe or the summer 2003 heat wave suffered in many parts of the continent (STARDEX, 2007). By analyzing the trend in the annual precipitation values, Karl et al. (1996) reported an increase in the frequency of high intensity precipitation events across the United States over the period of 1910 to 1996. Particularly since the 1990s, the occurrence of flood over the seven big river valleys in China is of high frequency, and both flood and geological disasters increased due to the increase of intense precipitation events and the consequent increase of their concentration degree (e.g. Zhang et al., 2008).

Xinjiang located in inland and far from oceans and is well known for the arid climate. This paper base on the day to day observed data of precipitation from 51 meteorological stations from 1961 to 2008, the climatic variations and tendencies of precipitation have been analyzed during the last 48 years. Also, apply STARS (Sequential t-test analysis of regime shifts) techniques, trends in annual and seasonal total precipitation and extreme daily precipitation, assessed for 1961-2008.

\section{DATA AND METHODS}

\section{Data preparation}

A dataset of daily precipitation amounts at 55 stations along with detailed metadata covering Xinjiang. They were provided by the National Climatic Centre of China, China Meteorological Administration. Several long-term meteorological data sets were used in this study. Monthly statistics were derived from a meteorological data set that consists of 55 Xinjiang observe stations. Meteorological variables are monthly precipitation, mean, maximum and minimum temperatures, and so on. Considering starting points of the precipitation and temperature series are different and 1961 to 2008 are decided as the study time interval for consistency of analysis. The stations with missing 
precipitation data of more than one year will be excluded from the dataset and the daily precipitation data at 51 stations are analyzed in this study.

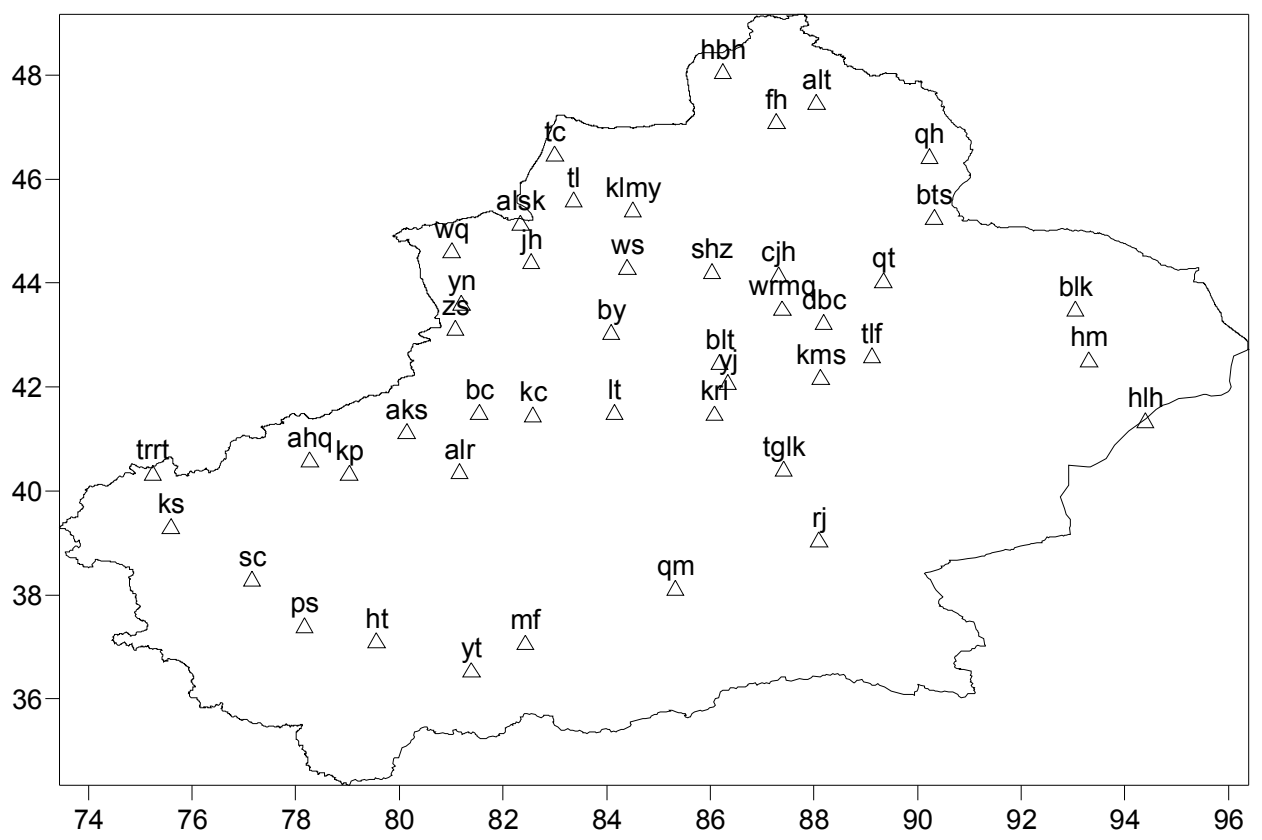

FIGURE 1. The study area and the location of meteorological station.

\section{Analysis techniques}

The AM series consists of the greatest events of each year in a given time period. The annual maximum consecutive dry/wet days (CDD/CWD) are defined as the longest consecutive days with daily precipitation of $<0.05 \mathrm{~mm} / \mathrm{d} />0.05 \mathrm{~mm} / \mathrm{d}$. Many other papers used $0.1 \mathrm{~mm} / \mathrm{d}$, but the Xinjiang is well known for the arid climate. It should be noted here that definition of the base precipitation differed from place to place. Therefore according to actual condition, we should using $0.05 \mathrm{~mm} / \mathrm{d}$ as a reference standard. Apply STARS (Sequential t-test analysis of regime shifts) techniques, analyzed trends in both annual total precipitation and CDD/CWD over Xinjiang, China. (Sergei N. Rodionov, 2004). The most import feature of the method may be its ability to detect a regime shift relatively early (Rudnick et al., 2003), and this is a new method for detecting undocumented discontinuities in Xinjiang region.

\section{TRENDS IN PRECIPITATION TOTALS}

\section{Annual precipitation}

The mean annual precipitation, 1961-2008, for the period of Xinjiang region was $130.1 \mathrm{~mm} /$ year (Fig.2 and Table.1). In general, over the last 48 years, the linear least square regression analysis reveals that the precipitation has increased at the rate of $0.5837 \mathrm{~mm} /$ year (Fig.2a). As reported earlier, the yearto-year pattern, which is one dominated by variability, with many "wet" years/periods and at least as many "dry" ones. Particularly noteworthy among the latter was the infamous drought of 1961-1965, Xinjiang is well known for the arid climate, droughts is serious natural disaster. (Jang et al.2004). During the 1961-1965 drought the mean annual region-wide precipitation fell to $112.8 \mathrm{~mm}$ (and only $103 \mathrm{~mm}$ in 1962), an event which caused widespread hardship still bitterly recalled throughout Xinjiang.

A majority of annual precipitation recorded across Xinjiang comes during the Summer although, as earlier noted, this is somewhat deceiving: because it is so hot, the mean potential evaporation or moisture loss values of these months far exceeds the moisture "income" in the form of rains. In other 
words, the rainy season is actually the dry season, i.e., the period of the year experiencing the largest average moisture deficiencies. The median of average annual summer (April-September) rainfall for the region was $60.3 \mathrm{~mm}$. The general trend (Fig. $2 \mathrm{~b}$ ) increased at the rate of $0.259 \mathrm{~mm} /$ year.

Examination of the century-long plot reveals that summer rainfall was if anything more prone to exaggerated variability than was annual precipitation. This is not particularly surprising, as the sixmonth "summer" includes the month of September, during which the region sometimes experiences heavy rains.

Winters in Xinjiang are relatively dry. The median of average winter (January) precipitation for the century was $12.5 \mathrm{~mm}$, less than $10 \%$ of the yearly mean. Compare to that of mean total precipitation and summer precipitation, the winter precipitation increase relatively minimal upward trend of 0.1446 $\mathrm{mm} /$ year (Fig.2c).

\section{Connection between changes in CWD, CDD and total precipitation}

In Fig.5a, we analyzed the annual total precipitation in Xinjiang during 1961 to 2008 by using STARS (Sequential t-test analysis of regime shifts) techniques trend test, based on measurements at about 50 meteorological stations nationally. Fig.5a shows that there was an obvious increasing trend from the 1961-2000 in Xinjiang, and during of 1961-2000, there were two regimes of the annual total precipitation; one shift happened in 1987. Before the shift, are-averaged time series of annual total precipitation was $118.6 \mathrm{~mm}$ cubic meters per year; after that, it decreased and are-averaged time series of annual total precipitation was $145.8 \mathrm{~mm}$ per year. From Fig.5b, it shows that the CWD also has two years in the 1961-2008 pattern, before 1991, average annual CWD of 4.5 days, increased after 1999 as the average annual CWD of 5.0 days. Fig.5c shows that in the 1961-2008 period, the pattern of change occurred in 2003, the average annual CDD decreased from the 61.8 to 54.4 days. It may be mentioned that Shi et al., (2002) in their study have reported the increasing trend in annual mean rainfall of these regions. Further more, the implications of these findings, which tend to support other indications of planetary warming (IPCC, 2001), suggest significant future challenges to the natural and human economies and ecologies of Xinjiang, China.

(b)

(a)

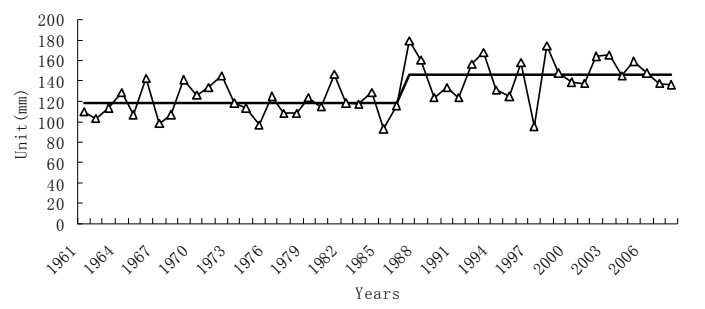

(c)

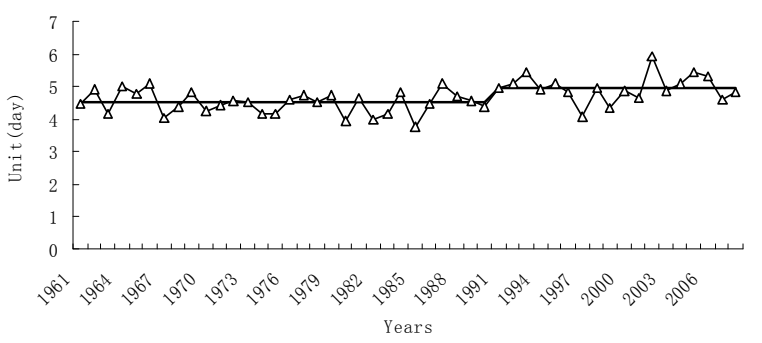

Years

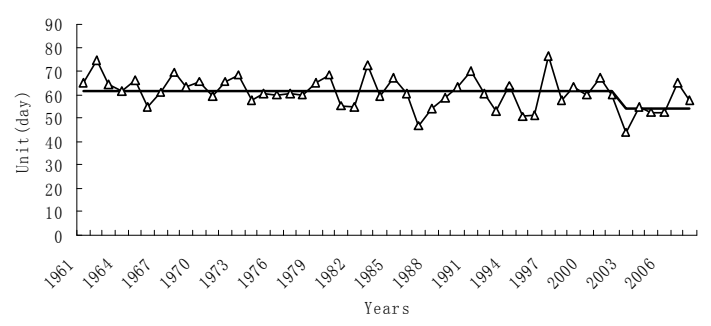

FIGURE 2. Regime Shift of (a) annual total precipitation; (b) annual CWD; (c) annual CDD. 


\section{Conclusions}

In the study, we apply STARS (Sequential t-test analysis of regime shifts) techniques, analyzed trends in both annual total precipitation and CDD/CWD over Xinjiang, China.

(1) In general, over the last 48 years, the linear least square regression analysis reveals that the precipitation has increased at the rate of $0.5837 \mathrm{~mm} /$ year. The median of average annual summer (April-September) rainfall for the region was $60.3 \mathrm{~mm}$. The general trend increased at the rate of 0.259 $\mathrm{mm} /$ year. Winters in Xinjiang are relatively dry. The median of average winter (January) precipitation for the century was $12.5 \mathrm{~mm}$, less than $10 \%$ of the yearly mean. Compare to that of mean total precipitation and summer precipitation, the winter precipitation increase relatively minimal upward trend of $0.1446 \mathrm{~mm} /$ year.

(2) During 1961-2008, the CDD decreases with the linear rate of $1.7 \mathrm{~d}$ per 10a, especially from mid 1980 s and the CWD increase with the rate of $0.1 \mathrm{~d}$ per $10 \mathrm{a}$. In particular, from 1988, average anomalous of most years was positive indicating a general increase trend before 1988 and a faster increase trend of the CWD after 1988.

(3) During of 1961-2000, there were two regimes of the annual total precipitation; one shift happened in 1987. Before the shift, are-averaged time series of annual total precipitation was $118.6 \mathrm{~mm}$ cubic meters per year; after that, it decreased and are-averaged time series of annual total precipitation was 145.8mm per year. The CWD also has two years in the 1961-2008 pattern, before 1991, average annual CWD of 4.5 days, increased after 1999 as the average annual CWD of 5.0 days. In the 19612008 period, the pattern of change occurred in 2003, the average annual CDD decreased from the 61.8 to 54.4 days.

\section{ACKNOWLEDGMENTS}

This research study was supported by the National Natural Science Foundation of China (Grant No. 41427805, 41171137); Henan province science and technology research project (152102310354); Henan province social science popularization planning project (069); Jinan University social science project (15YB07); Shandong province statistics society subject (SQ15080) and China Branch Coordination Department Project (DXB-ZKQN-2016-039).

\section{REFERENCES}

1. IPCC. Climate change 2001: impacts, adaptation, and vulnerability. In: McCarthy JJ, Canziani OF, Leary NA, Dokken DJ, White KS (eds) Contribution of working group II to the third assessment report of the intergovernmental panel on climate change. Cambridge University Press, Cambridge(2001).

2. Jiang Fengqing, Hu Ruji and Yang Yaohui. Abrupt Change in the Time Sequences of Flood Disasters in Xinjiang and Its Possible Climatic Reasons. Journal of Glaciology and Geocryology 26, 674-681(2004).

3. Karl T, Knight R, Easterling D, Quayle R. Indices of climate change for the United States. Bull Am Meteorol Soc77, 279-292(1999).

4. Rudnick, D.L., and R. E. Davis. Red noise and regime shift, Deep-Sea Research 50, 691699(2003).

5. Sergei N. Rodionov. A sequential algorithm for testing climate regime shifts. Geophysical Research Letters 31, 1-4 (2004).

6. STARDEX: STAtistical and Regional dynamical Downscaling of EXtremes for european regions, EVK2-CT-2001-00115, 5th Framework European programme project (2002-2005). http:// www.cru.uea.ac.uk/cru/projects/stardex/ 
7. Shi Yafeng, Shen Yongping, Hu Ruji. Preliminary study on signal, impact and foreground of climatic shift from warm dry to warm-humid in Northwest China. Journal of Glaciology and Geocryology 24, 219-226 (2002).

8. Xu Yuqing, Miao Qiuju and She Yongping. The Year 2008: Gold Warming Continued, Extreme Events Occurred Frequently. Advances in climate change research 5, 56-60(2009).

9. Zhang Qiang, Chong-yu Xu, Zengxin Zhang, Yongqin David Chen, Chun-ling Liu. Spatial and temporal variability of precipitation maxima during 1960-2005 in the Yangtze River basin and possible association with large-scale circulation. Journal of Hydrology 353, 215-227(2008). 